\title{
Mouse model of carbon tetrachloride induced liver fibrosis: Histopathological changes and expression of CD133 and epidermal growth factor
}

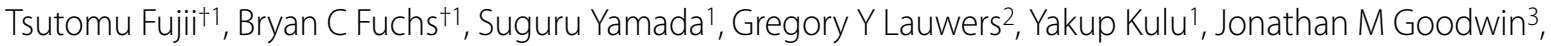 \\ Michael Lanuti ${ }^{3}$ and Kenneth K Tanabe*1
}

\begin{abstract}
Background: In the setting of chronic liver injury in humans, epidermal growth factor (EGF) and EGF receptor (EGFR) are up-regulated and have been proposed to have vital roles in both liver regeneration and development of hepatocellular carcinoma (HCC). Chronic liver injury also leads to hepatic stellate cell (HSC) differentiation and a novel subpopulation of HSCs which express CD133 and exhibit properties of progenitor cells has been described in rats. The carbon tetrachloride $\left(\mathrm{CCl}_{4}\right)$-induced mouse model has been historically relied upon to study liver injury and regeneration. We exposed mice to $\mathrm{CCl}_{4}$ to assess whether EGF and CD133+ HSCs are up-regulated in chronically injured liver.

Methods: $\mathrm{CCl}_{4}$ in olive oil was administered to strain $\mathrm{A} / \mathrm{J}$ mice three times per week by oral gavage.

Results: Multiple well-differentiated HCCs were found in all livers after 15 weeks of $\mathrm{CCl}_{4}$ treatment. Notably, HCCs developed within the setting of fibrosis and not cirrhosis. CD133 was dramatically up-regulated after $\mathrm{CCl}_{4}$ treatment, and increased expression of desmin and glial fibrillary acidic protein, representative markers of HSCs, was also observed. EGF expression significantly decreased, contrary to observations in humans, whereas the expression of amphiregulin, another EGFR ligand, was significantly increased.
\end{abstract}

Conclusions: Species-specific differences exist with respect to the histopathological and molecular pathogenesis of chronic liver disease. $\mathrm{CCl}_{4}$-induced chronic liver injury in $\mathrm{A} / \mathrm{J}$ mice has important differences compared to human cirrhosis leading to HCC.

\section{Background}

Hepatocellular carcinoma (HCC) is the fifth most common cancer worldwide and is the third leading cause of cancer mortality [1]. Eighty percent of HCCs develop in the context of chronic liver diseases, as chronic liver injury generally induces liver fibrosis, followed by cirrhosis [2]. In an attempt to model this process, carbon tetrachloride $\left(\mathrm{CCl}_{4}\right)$ has been widely used to experimentally induce liver injury in rodents. A single dose of $\mathrm{CCl}_{4}$ leads to centrizonal necrosis and steatosis [3], while prolonged administration leads to liver fibrosis, cirrhosis, and HCC

\footnotetext{
*Correspondence: ktanabe@partners.org

1 Division of Surgical Oncology, Massachusetts General Hospital Cancer Center and Harvard Medical School, Boston, USA

+ Contributed equally

Full list of author information is available at the end of the article
}

[4]. $\mathrm{CCl}_{4}$ impairs hepatocytes directly by altering the permeability of the plasma, lysosomal, and mitochondrial membranes. Highly reactive free radical metabolites are also formed by the mixed function oxidase system in hepatocytes via CYP2E1, causing severe centrilobular necrosis $[5,6]$. This model has been used extensively to examine the pathogenesis of cirrhosis.

Liver fibrosis is the pathologic result of ongoing chronic inflammatory liver diseases and is characterized by hepatic stellate cell (HSC) proliferation and differentiation to myofibroblast-like cells, which deposit extracellular matrix (ECM) and collagen. Quiescent HSCs are vitamin A storing cells in the space of Disse, and they account for about $15 \%$ of the total number of liver cells [7]. The activation of HSCs is mediated by reactive oxy- 
gen species and various cytokines, including transforming growth factor (TGF)- $\beta$, tumor necrosis factor (TNF)$\alpha$, and platelet-derived growth factor (PDGF), as well as other factors which are released from the damaged hepatocytes and activated Kupffer cells [8]. The activated HSCs produce large amounts of ECM components, such as laminin and collagen type IV, in an accelerated fashion, resulting in fibrotic change of the liver. The number of HSCs was found to be increased in alcoholic liver disease and in other animal models of chronic liver disease [8]. HSCs are further characterized by their stellate-shaped morphology and expression of desmin and glial fibrillary acidic protein (GFAP). A novel subpopulation of HSCs in rats has been described to exhibit properties of progenitor cells and express CD133, originally thought to be a marker of endothelial progenitor cells (EPCs), hematopoietic stem cells, and other stem cells [9]. This finding gave rise to the hypothesis that CD133+ HSCs are up-regulated in chronically injured liver.

Epidermal growth factor (EGF), a polypeptide mitogen, and its tyrosine kinase receptor (EGFR) have been proposed to have vital roles in liver regeneration and transformation $[10,11]$. EGF and EGFR are highly elevated in human cirrhotic livers [12]. However, to the best of our knowledge, the expression of EGF and EGFR in the injured liver in mouse models has not been fully investigated.

In the current study, we exposed mice to $\mathrm{CCl}_{4}$ to create fibrosis, cirrhosis, and HCC and assessed histopathology, EGF expression, and HSC populations. We observed that CD133+ HSCs are recruited during chronic liver injury in $\mathrm{CCl}_{4}$-treated mice. Multiple HCCs were found in the livers of all mice after 15 weeks of $\mathrm{CCl}_{4}$ treatment; however, the pathological findings and EGF expression patterns in the injured liver were different from those previously reported in humans, suggesting that species-specific differences exist with respect to the histopathological and molecular pathogenesis of chronic liver injury.

\section{Methods}

\section{Animals and Experimental Design}

Strain A/J male mice at approximately 5 weeks of age were purchased from Jackson Laboratory (Bar Harbor, $\mathrm{ME}$ ). As shown in Figure 1, all mice were randomly assigned to two groups: a control group $(\mathrm{n}=15)$ and a $\mathrm{CCl}_{4}$ group $(\mathrm{n}=25)$. Mice were treated three times a week for 17 weeks with either $0.04 \mathrm{cc}$ of a 40 percent solution of $\mathrm{CCl}_{4}$ (Sigma, St. Louis, MO) in olive oil or with vehicle by oral gavage. Mice were subsequently sacrificed at the indicated times after a one-week washout to eliminate acute effects of $\mathrm{CCl}_{4}$. The liver was sectioned and fixed in phosphate-buffered $10 \%$ formaldehyde for histological analysis. The remaining portions of the liver were col- lected in RNase-free tubes and snap-frozen in liquid nitrogen. Mice were classified into three groups, depending on the time of sacrifice: Time point I (4-6 weeks), Time point II (15-17 weeks), Time point III (24-30 weeks).

\section{Histopathological Examination}

Each formaldehyde-fixed sample was embedded in paraffin, cut into $5 \mu \mathrm{m}$-thick sections and stained with hematoxylin-eosin (H-E), Masson's trichrome and Sirius red according to standard procedures. Those from $\mathrm{CCl}_{4}$ and control groups at Time point II were stained with antibodies for CD133, desmin and alpha-smooth muscle actin ( $\alpha$-SMA) (all from Abcam; Cambridge, MA) according to the manufacturer's instructions. All slides were reviewed by the same pathologist.

\section{Quantitative Real-Time Polymerase Chain Reaction}

Quantitative real-time polymerase chain reaction (PCR) was carried out as described previously [11]. Briefly, total RNA was extracted from a small piece of frozen mouse liver using TRIzol (Invitrogen, Carlsbad, CA) according to the manufacturer's instructions.

The mRNA expression of EGF, EGFR, transforming growth factor-alpha (TGF- $\alpha$ ), heparin-binding EGF-like growth factor (HB-EGF), amphiregulin (AREG), desmin, GFAP, CD133 and vascular endothelial growth factor receptor 2 (VEGFR2) was analyzed. The mRNA expression was normalized to the expression of GAPDH. Primer sequences were as follows: SEQ NO.1 EGF forward (NM_010113.1 87-106 bp) GGCTTGGAACTTTCCATCAA, SEQ NO.2 EGF reverse (NM_010113.1 333-314 bp) CAGGTCCTTCTGCACCTCTC, SEQ NO.3 EGFR forward (NM_207655.1 349-368 bp) GGCGTTGGAGGAAAAGAAAG, SEQ NO.4 EGFR reverse (NM_207655.1 471-452 bp) TTCCCAAGGACCACTTCACA, SEQ N0.5 TGF- $\alpha$ forward (NM_031199.1 23952414 bp) CAGGGAGCAACACAAATGGA, SEQ N0.6 TGF- $\alpha$ reverse (NM_031199.1 2491-2471 bp) AGCCTCCAGCAGACCAGAAA, SEQ NO.7 HB-EGF forward (NM_010415.2 1147-1166 bp) GAAAGCAGGATCGAGTGAGC, SEQ NO.8 HB-EGF reverse (NM_010415.2 1369-1350 bp) CTTGCGGCTACTTGAACACA, SEQ NO.9 AREG forward (NM_009704.3 739-758 bp) GACTCACAGCGAGGATGACA, SEQ NO.10 AREG reverse (NM_009704.3 987-968 bp) GGCTTGGCAATGATTCAACT, SEQ NO.11 desmin forward (NM_010043.1 1723-1742 bp) AGCTCAAGTCATCGCCCTTC, SEQ. NO. 12 desmin reverse (NM_010043.1 1801-1781 bp) GCAGATCCCAACACCCTCTC, SEQ NO.13 GFAP forward (NM_010277.1 1078-1097 bp)AACCGCATCACCATTCCTGT, SEQ NO.14 GFAP reverse (NM_010277.1 1214-1196 bp) ACCTCACCATCCCGCATCT, SEQ NO.15 CD133 for- 


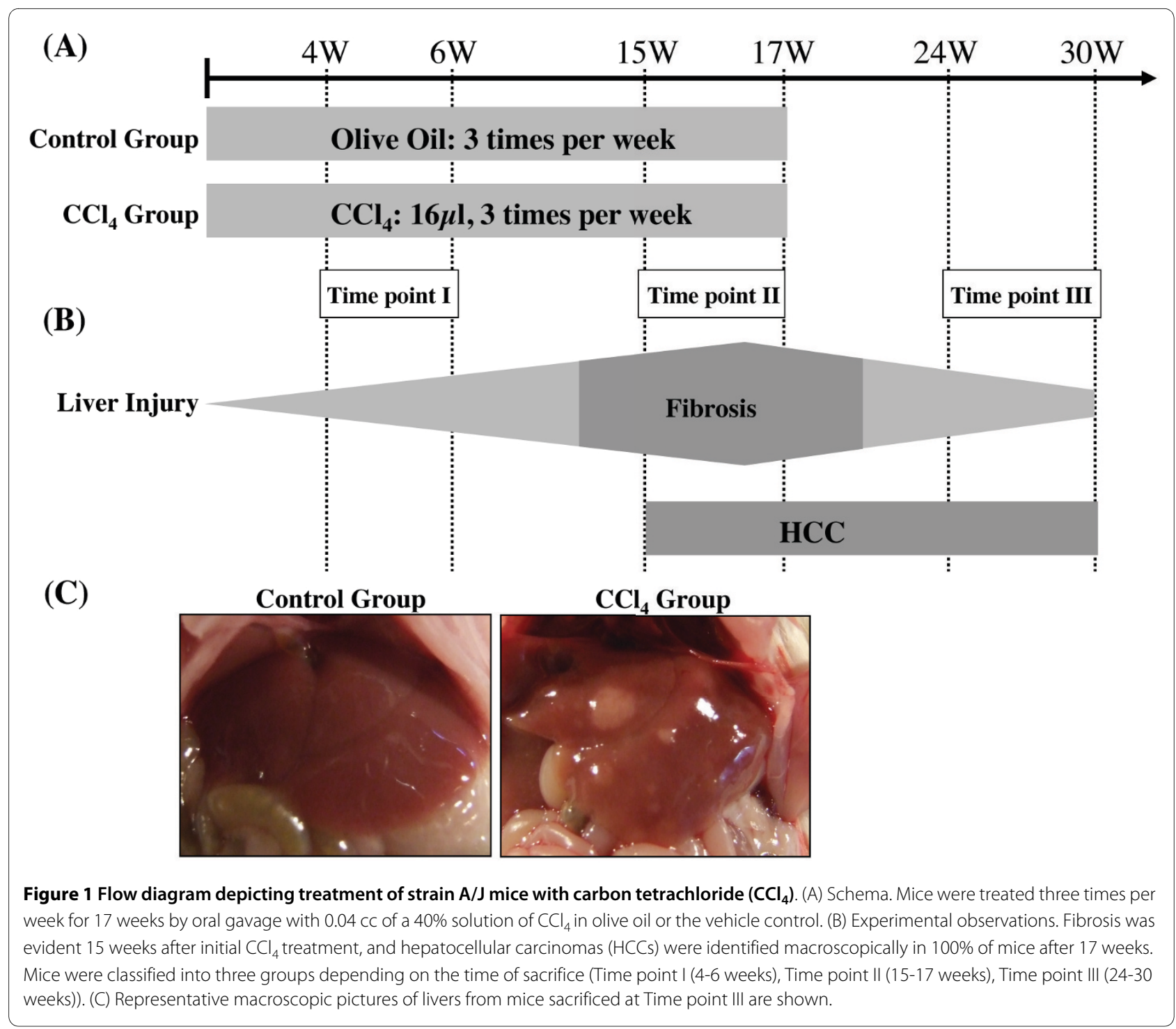

ward (NM_008935.1 1698-1717 bp) GAAAAGTTGCTCTGCGAACC, SEQ NO.16 CD133 reverse (NM_008935.1 1893-1874 bp) TCTCAAGCTGAAAA GCAGCA, SEQ NO.17 VEGFR2 forward (NM_010612.1 3574-3593 bp) ATGCGGGCTCCTGACTACAC, SEQ NO.18 VEGFR2 reverse (NM_010612.1 3683-3664 bp) CCCAAATGCTCCACCAACTC, SEQ NO.19 GAPDH forward (NM_008084 543-562 bp) AACTTTGGCATTGTGGAAGG, SEQ NO.20GAPDH reverse (NM_008084 765-746 bp) ACACATTGGGGGTAGGAACA. All reactions were performed in duplicate, and the experiment was repeated to ensure reproducible results.

\section{Enzyme-Linked Immunosorbent Assay (ELISA)}

Liver tissue samples were homogenized in RIPA Buffer (Boston BioProducts, Worcester, MA) containing protease inhibitors (Sigma). Homogenates were centrifuged twice at $10,000 \times g$ for 30 minutes at $4^{\circ} \mathrm{C}$, and the pellets were discarded. Protein concentration was determined using the bicinchoninic acid (BCA) method (Pierce Chemical Co., Rockford, IL). The protein level of EGF was examined using a Quantikine Immunoassay kit (R\&D Systems Inc., Minneapolis, MN) according to the manufacturer's instructions. All samples were measured in triplicate.

\section{Western Blotting}

Western blotting was carried out as described previously [11]. Briefly, cellular lysates $(35 \mu \mathrm{g})$ were prepared in Laemmli's reducing sample buffer (Boston BioProducts), separated by electrophoresis on $4-20 \%$ polyacrylamide gradient gels (Cambrex Bio Science, Walkersville, MD). Membranes were incubated overnight at $4{ }^{\circ} \mathrm{C}$ with primary antibodies raised against EGFR, phospho-EGFR (Tyr 1068) and proliferating cell nuclear antigen (PCNA) (all from Cell Signaling Technology, Beverly, MA) and 
then incubated with appropriate secondary antibodies for $1 \mathrm{~h}$ at room temperature. An antibody directed against $\beta$ actin (Abcam) was used to verify equal loading. Each western blot was repeated to ensure reproducible results.

\section{Statistical Analysis}

The relative mRNA expression levels were calculated from the quantified data. An unpaired $t$ test was used to analyze the differences, and a non-parametric test was used (Mann-Whitney $U$ test) if the distribution was abnormal. All the statistical analyses were performed using Stat View 5.0 (Abacus Concepts, Berkeley, CA). Data are expressed as mean \pm SD. $P<0.05$ denoted the presence of a statistically significant difference.

\section{Results}

\section{Histological Analysis}

As shown in Figure 1A, mice either received $\mathrm{CCl}_{4}$ solution via oral gavage three times per week or olive oil alone as control. In the $\mathrm{CCl}_{4}$ group, mice became lethargic and lean, and their fur became lusterless. One or multiple nodules, as many as 10 occurring in one liver, were found macroscopically on the surface of the entire liver in 100\% of mice after 15 weeks of $\mathrm{CCl}_{4}$ treatment (Figure 1B, C). Tumors size varied from 0.1 to $1.2 \mathrm{~cm}$ in diameter.

Liver samples were stained with H-E and Masson's trichrome to evaluate histopathologic changes and tissue fibrosis (Figure 2A, B). H-E staining of liver tissue from all control mice at each time point revealed normal cellular architecture (Figure 2A). Liver tissue from $\mathrm{CCl}_{4}$ Group at Time point I (4-6 weeks) demonstrated some cellular damage and centrilobular congestion with no infiltration of inflammatory cells. Liver tissue from $\mathrm{CCl}_{4}$ Group at Time point II (15-17 weeks) demonstrated increased mitotic activity, intense neutrophilic infiltration, extensive fatty changes and severe centrilobular necrosis. Welldifferentiated $\mathrm{HCCs}$ and severe fatty changes were observed in livers from the $\mathrm{CCl}_{4}$ Group at Time point III (24-30 weeks). Masson's trichrome staining of the liver was performed to assess collagen distribution (Figure 2B). All control mice at each time point revealed a normal distribution of collagen. Extensive collagen deposition and pseudolobular formation was only evident in liver tissue from $\mathrm{CCl}_{4}$ Group at Time point II. When examined by a pathologist, the livers were determined to have bridging fibrosis (Ishak score 3-4). As previously mentioned, welldifferentiated HCCs were confirmed microscopically in all mice after 15 weeks (Time point II) of $\mathrm{CCl}_{4}$ treatment; however, most notably, no evidence of cirrhosis (i.e. the presence of regenerative nodules) was identified in these livers, even in those with HCC. Given that the goal of this study was to create HCC in the setting of cirrhosis and HCCs had already developed in the absence of cirrhosis,
$\mathrm{CCl}_{4}$ treatment was stopped at this point. Interestingly, the degree of inflammation and collagen deposition decreased at Time point III, suggesting that the liver repaired itself.

To further assess the extent of fibrosis/cirrhosis after $\mathrm{CCl}_{4}$ treatment, Sirius red staining was performed on liver sections from each time point (Figure 3). The results were similar to the Masson's trichrome stains. Control mice had a normal distribution of collagen, whereas those treated with $\mathrm{CCl}_{4}$ at Time point I demonstrated early signs of fibrosis. Mice treated with $\mathrm{CCl}_{4}$ at Time point II demonstrated bridging fibrosis and those at Time point III had less collagen deposition suggesting again that the liver repaired itself.

\section{EGF and EGFR Expression}

We examined 11 control livers (Time point I, II, III; $\mathrm{n}=4$, $\mathrm{n}=2, \mathrm{n}=5$, respectively), 4 damaged but non-fibrotic livers (Time point I), 5 fibrotic livers (Time point II), and 8 non-cancerous livers (Time point III) for EGF mRNA expression by quantitative real-time PCR. EGF mRNA expression markedly decreased during liver injury (Figure 4A). To investigate EGF protein levels, ELISA for EGF was conducted in the same liver samples. EGF protein expression in the injured liver was significantly lower than in the normal liver (Figure 4B). EGFR mRNA expression also decreased significantly with increasing degree of liver injury (Figure 4C). Interestingly, we observed that total EGFR levels decreased with $\mathrm{CCl}_{4}$ administration while p-EGFR levels increased. The decrease in total EGFR in the presence of increased pEGFR is likely a result of ligand-mediated receptor endocytosis [13]. This is consistent with decreased total EGFR protein expression observed in proliferating hepatocytes [14] which we confirmed by increased PCNA expression in response to $\mathrm{CCl}_{4}$ administration (Figure 4D). A correlation appears to exist then between p-EGFR levels and PCNA and therefore probably hepatocyte proliferation.

Since we observed no increase in EGF expression, we examined the expression of several other EGFR ligands including HB-EGF, AREG and TGF- $\alpha$, which has been reported to play an essential role in the regenerating liver [15]. TGF- $\alpha$ mRNA expression in livers treated with $\mathrm{CCl}_{4}$ was significantly higher than in control livers (Figure 5A), while HB-EGF levels did not change (Figure 5B). AREG was dramatically increased in livers treated with $\mathrm{CCl}_{4}$ (Figure 5C).

\section{CD133 Expression}

To evaluate HSCs in injured livers, quantitative real-time PCR was performed for desmin and GFAP, known to be representative markers of HSCs [16]. Increased expression of both desmin and GFAP mRNA was observed in 


\section{(A) H-E stain}

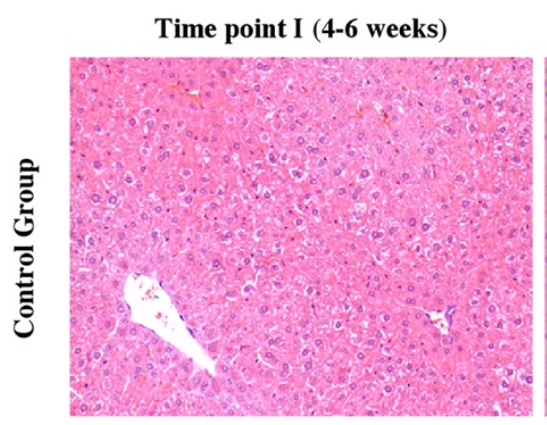

\section{Time point II (15-17 weeks)}


Time point III (24-30 weeks)
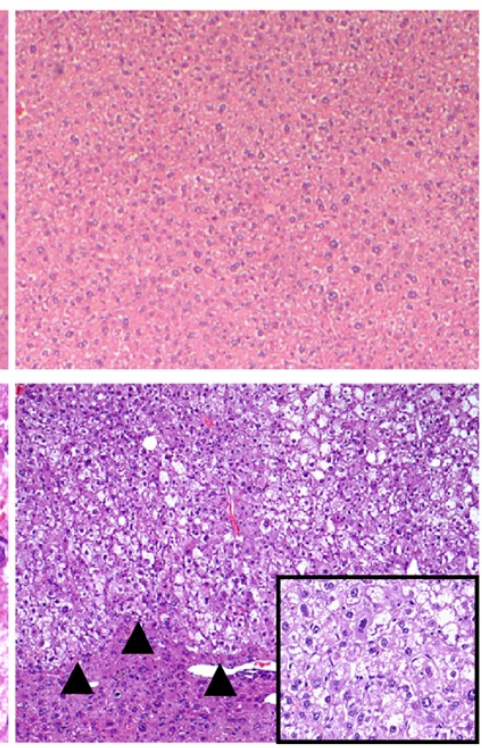

\section{(B) Masson's trichrome stain}
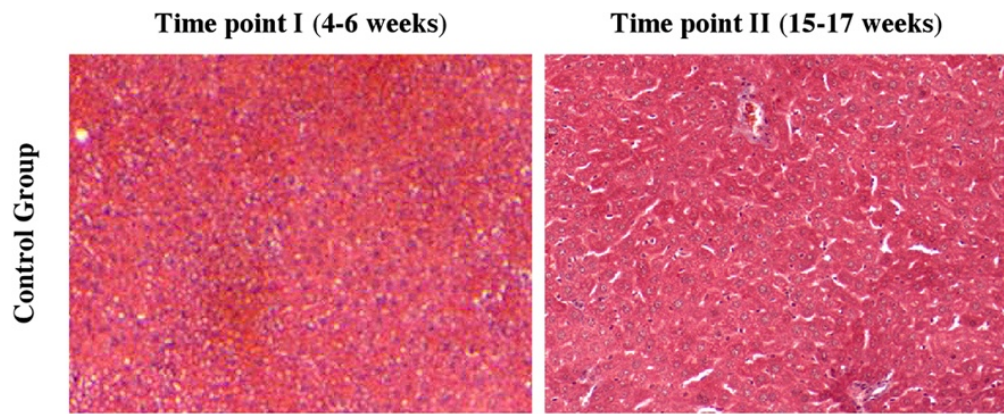

Time point III (24-30 weeks)
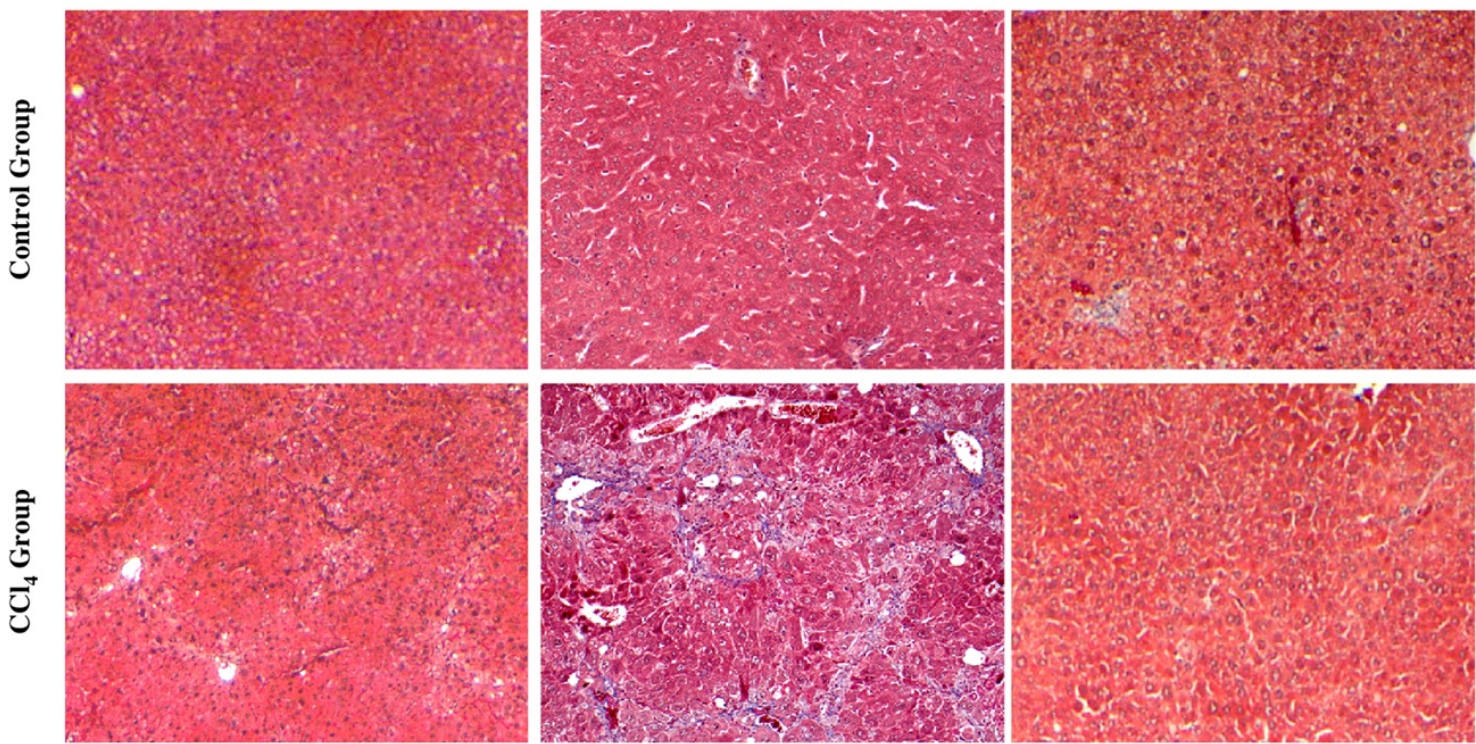

Figure 2 Histopathological examination of mouse livers revealed fibrosis and HCC but no evidence of cirrhosis. (A) Liver tissue from all control mice at each time point gavaged with olive oil alone revealed normal cellular architecture (upper, $\mathrm{H}$-E, original magnification $\times 40$ ). Liver tissue from $\mathrm{CCl}_{4}$ Group at Time point I revealed some damage of liver cells and centrilobular congestion with no infiltration of inflammatory cells (bottom left, $\mathrm{H}$ $\mathrm{E}$, original magnification $\times 200$ ). Liver tissue from $\mathrm{CCl}_{4}$ Group at Time point II had increased mitotic activity (arrows), intense neutrophilic infiltration, extensive fatty changes and severe centrilobular necrosis (bottom middle, $\mathrm{H}-\mathrm{E}$, original magnification $\times 600$ ). Liver tissue from $\mathrm{CCl}_{4} \mathrm{Group}_{\text {at Time }}$ point III revealed well-differentiated HCCs (arrowheads) with severe fatty changes (bottom right, H-E, original magnification $\times 40$ ). High-power view ( $\times 200)$ of tumor cells is shown. (B) Masson's trichrome staining of the liver from all control mice at each time point revealed normal lobular architecture and a normal distribution of collagen (upper). Masson's trichrome staining of liver tissue from $\mathrm{CCl}_{4}$ Group at Time point II revealed extensive collagen deposition and pseudolobular formation, suggesting liver fibrosis (bottom middle). The degree of collagen deposition decreased at Time point III (bottom right). (original magnification $\times 40$ ). 




Figure 3 Histopathological examination of mouse livers by Sirius red staining. Sirius red staining of the liver from all control mice at each time point revealed normal lobular architecture and a normal distribution of collagen (upper). Sirius red staining of liver tissue from $\mathrm{CCl}_{4} \mathrm{Group}_{\text {at Time }}$ point II revealed extensive collagen deposition and pseudolobular formation, indicative of bridging fibrosis (bottom middle). The degree of collagen deposition decreased at Time point III (bottom right). (original magnification $\times 40$ ).

the more extensively injured liver samples (Figure 6A, B). Furthermore, CD133 was also dramatically up-regulated in the livers of $\mathrm{CCl}_{4}$-treated mice (Figure $6 \mathrm{C}$ ). Upon withdrawal of $\mathrm{CCl}_{4}$, the expression of CD133 returned to control levels in the surrounding normal tissues but remained elevated in the tumors. CD133 positive cells probably correspond to HSCs as an immunohistochemical study revealed that CD133, desmin and $\alpha$-SMA (a marker for activated HSCs) localized to the same regions in $\mathrm{CCl}_{4}$-treated mouse livers (Figure 7). Further, the mRNA expression of VEGFR2, reported to be one of the surface markers of EPCs, was not altered (Figure 6D).

In order to exclude the possibility that $\mathrm{CCl}_{4}$ simply promotes CD133 expression in existing parenchyma cells, an in vitro study was also conducted. Hepa 1-6 (mouse hepatoma), THLE-5B (non-tumorigenic human liver), HepG2 (human hepatoblastoma) and SNU-182 (human hepatoma) cell lines were treated with $4 \mathrm{mM} \mathrm{CCl}_{4}$ for 24 hours, and CD133 mRNA expression was determined. $\mathrm{CCl}_{4}$ treatment did not increase CD133 expression in human or mouse cell lines or in non-tumorigenic or cancer cell lines (data not shown). Further, in this small sampling, no differences in CD133 expression were seen between non-tumorigenic and tumorigenic cell lines from the same species.

\section{Discussion}

$\mathrm{CCl}_{4}$-induced toxicity and its mechanisms have been extensively investigated after oral administration to rodents. A large number of rat models have been reported to develop both liver cirrhosis and HCC using $\mathrm{CCl}_{4}$ or diethylnitrosamine. In the current study, we generated well-differentiated $\mathrm{HCCs}$ in the livers of all $\mathrm{CCl}_{4}$ treated strain A/J mice. Fibrosis but not cirrhosis was identified in these livers, even in those with HCCs. The cessation of oral gavage of $\mathrm{CCl}_{4}$ after 17 weeks may explain why cirrhosis did not develop although HCC clearly developed before any signs of cirrhosis. In previous reports of a rat model, liver cirrhosis induced by toxic agents preceded the development of HCC, like in humans $[17,18]$. In this study, HCCs were obviously generated in fibrotic, not cirrhotic, livers.

Many investigators have previously reported their findings in mice treated with $\mathrm{CCl}_{4}$, each with different mouse strains and $\mathrm{CCl}_{4}$ administration schedules. We therefore reviewed eight published reports of mouse models of liver "cirrhosis" induced only by $\mathrm{CCl}_{4}$ to assess fibrosis, regenerative nodules, and cirrhosis [19-26]. One report of a transgenic mouse model was also reviewed [27]. Of the nine models previously reported in the literature, only the model by Xue et al. shows incomplete cirrhosis (Ishak 

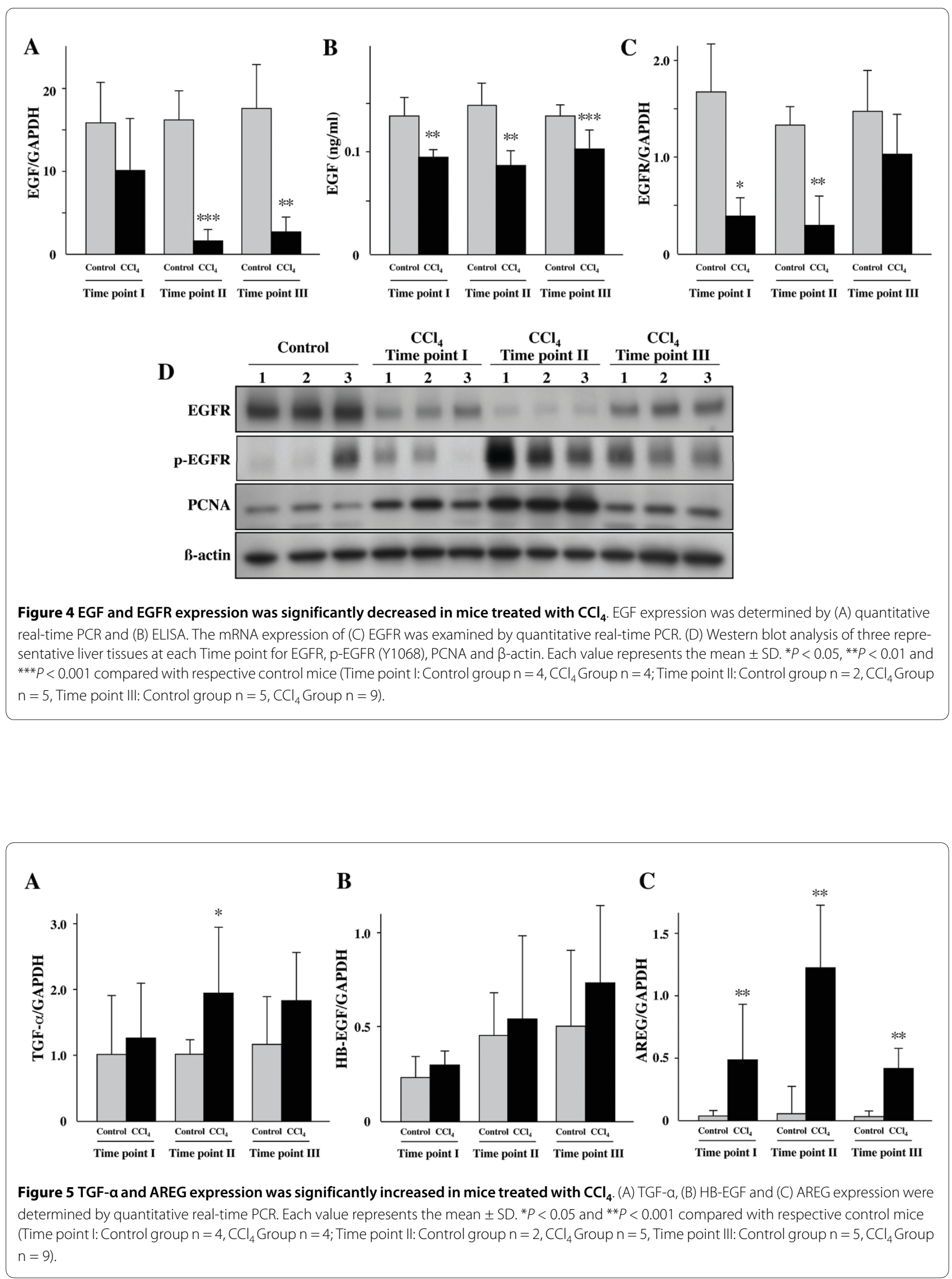


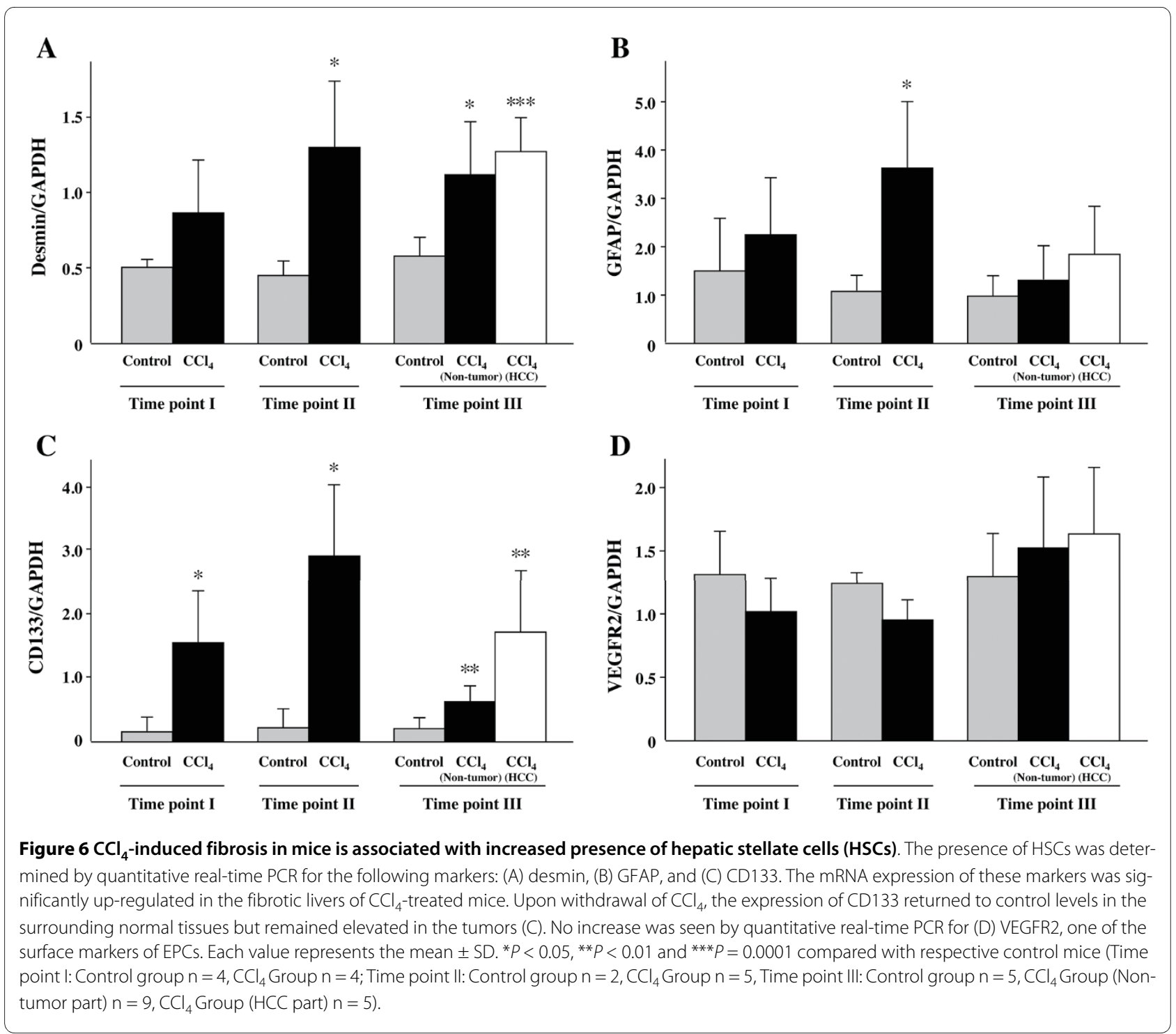

score $=5$ ) with portal fibrosis, bridging fibrosis, and regenerative nodules [23,28]. Two other models show changes similar to ours $[19,24]$, all the others showed only limited portal fibrosis and bridging fibrosis with no regenerative nodules. Thus, it may be more difficult to induce cirrhosis in mice.

The mechanism mobilizing the normally quiescent hepatocyte into mitogenesis in injured liver is poorly understood, although accumulating data suggest that EGF and TGF- $\alpha$, specific ligands of EGFR, play a central role in initiating and/or sustaining the early growth response program $[15,28,29]$. We obtained evidence that both mRNA and protein expression of EGF significantly decreased during liver injury, but increased during repair after the withdrawal of $\mathrm{CCl}_{4}$. The transcription of EGF was shown to be extremely low in control livers but was highly elevated in cirrhotic livers of human patients, and
EGF expression was increased significantly during the course of cirrhosis development in a rat model $[12,30]$. Therefore, histopathological changes and EGF expression patterns observed in this mouse model were different from those previously reported in rats and humans. Consistent with previously reported rat models of liver cirrhosis, EGFR expression was shown to decrease in this mouse study, whereas it has been reported to increase in human cirrhosis patients $[31,32]$. However, these results are difficult to interpret as decreased levels of total EGFR observed in animal models might be due to ligand-mediated receptor endocytosis in response to elevated signaling.

Combined with our histopathological analysis of previously published reports, our results indicate that there are species-specific differences in liver regeneration in response to cytokines and growth factors. Previous inves- 


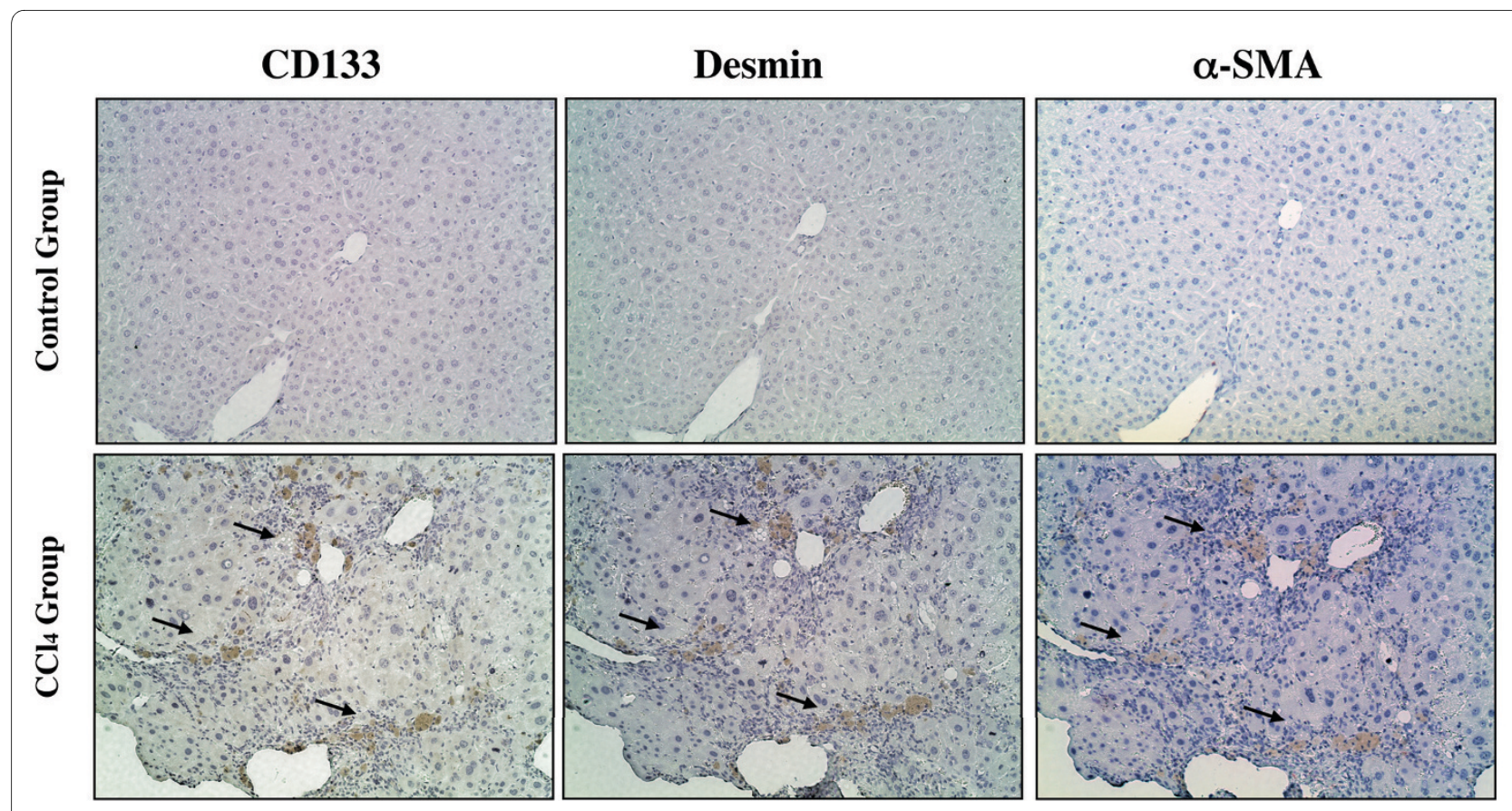

Figure $7 \mathrm{CD} 133$, desmin and a-SMA localize together in $\mathrm{CCl}_{4}$-treated mouse livers. Liver sections from $\mathrm{CCl}_{4}$ and control groups at Time point II were stained with antibodies for CD133, desmin and a-SMA.

tigators have provided evidence of the differences in the response to hepatotoxicity in the livers of rodents. High levels of inhalation exposure to $\mathrm{CCl}_{4}$ resulted in liver cirrhosis in rats but in neither fibrosis nor cirrhosis in mice [33]. Furthermore, inflammation of the liver was almost absent in rats after common bile duct ligation but was more pronounced in mice [34]. It was also reported that the lack of circulating EGF in sialoadenectomized mice did not decrease the proportion of hepatocytes that replicate during liver regeneration after partial hepatectomy [35], whereas removal of the salivary glands in rats led to complete blockage of liver regeneration [36]. It would appear that other EGFR ligands might be critically involved in liver regeneration in mice instead of EGF $[28,37]$. For example, both TGF- $\alpha$ and AREG increased in injured livers in this study. TGF- $\alpha$ has previously been shown to increase in previous reports of rats and humans and AREG has previously been shown to participate in the development of mouse liver fibrosis [38]. Importantly, AREG has also been shown to contribute to the neoplastic phenotype of human HCC cells (Castillo 2006 Cancer Research) and therefore the CCL4 model could be used to further study the role of AREG in hepatocarcinogenesis.

We observed that the expression of both desmin and GFAP, known to be markers of HSCs, were significantly elevated in injured liver samples. This finding implicates increased numbers of $\mathrm{HSCs}$ in the livers of $\mathrm{CCl}_{4}$-treated mice. In a recent study, Kordes et al. demonstrated that 20-40\% of HSCs expressed CD133 and exhibited properties of progenitor cells in rats [9]. Motivated by this report, we also examined CD133 expression in the injured livers of mice. The mRNA expression of CD133 was observed to be up-regulated in more injured liver as was desmin and GFAP. Further, immunohistochemical staining revealed that $\mathrm{CD} 133$, desmin and $\alpha$-SMA localized together in $\mathrm{CCl}_{4}$-treated mice livers. $\mathrm{CD} 133$ has been recognized as a cell surface marker of stem/progenitor cells. However, the mRNA expression of VEGFR2, reported to be one of the markers of both early and mature EPCs was not associated with the degree of the liver injury. Our results indicated that $\mathrm{CD} 133$ positive cells probably correspond to HSCs, not EPCs, and that CD133+ HSCs increased through chronic liver injury in $\mathrm{CCl}_{4}$-treated mice. Finally, CD133 expression returned to control levels in the surrounding non-cancerous tissues but remained elevated in HCCs.

CD133+ cells have been identified in the ductular reactions of chronically damaged human livers [39]. CD133 has been implicated as a marker for cancer stem cells of epithelial origin [40], and consistent with this, CD133+ cells isolated from human HCC cell lines have been reported to have cancer stem cell properties [41,42]. Further, CD133 expression has been reported to be associated with poor disease-free survival in HCC patients but was negatively associated with $\mathrm{HBsAg}$, implicating a non- 
viral origin of CD133 expression in HCC. Here, we have shown that a chemical toxicity induces CD133 expression in the liver. Overall, our results suggest an association between CD133 upregulation and tumor generation although details must be elucidated by further investigation.

Our results suggest that the use of $\mathrm{CCl}_{4}$-induced chronic liver injury in mice has important differences compared to human cirrhosis. In humans, HCCs typically develop within the setting of cirrhosis; however, in this study, no evidence of cirrhosis was seen, and HCCs developed within a setting of fibrosis. Furthermore, EGF expression decreased significantly during chronic liver injury, whereas it has been shown to increase during development of human cirrhosis. These results suggest that species-specific differences exist with respect to the histopathological and molecular pathogenesis of chronic liver disease. The dramatic up-regulation of CD133 is a notable finding, and the contribution of CD133+ HSCs to liver regeneration and tumor progression await further studies in rodents and humans.

\section{Abbreviations}

EGF: epidermal growth factor; EGFR: epidermal growth factor receptor; HCC: hepatocellular carcinoma; HSC: hepatic stellate cell; $\mathrm{CCl}_{4}$ : carbon tetrachloride; TGF: transforming growth factor; HB-EGF: heparin-binding EGF-like growth factor; AREG: amphiregulin; GFAP: glial fibrillary acidic protein; EPC: endothelial progenitor cell

\section{Competing interests}

The authors declare that they have no competing interests.

\section{Authors' contributions \\ Study Concept and Design: TF, BCF and KKT. Acquisition of Data: TF, BCF, GYL, YK, JMG and SY. Analysis and Interpretation of Data:TF, BCF, GYL, YK, JMG, SY, ML and KKT. Drafting of the Manuscript: TF, BCF, GYL and KKT. Statistical Analysis: TF, BCF and KKT. Obtained Funding: BCF, YK and KKT. Administrative, technical or material support: TF, BCF, GYL, YK, JMG, SY, ML and KKT. Study Supervision: TF, BCF and KKT. All the authors have read and approved the final manuscript.}

\section{Acknowledgements}

This work was supported by the U.S. National Institute of Health $(\mathrm{NIH})$ grant 2R01CA076183 (KKT), Deutsche Forschungsgemeinschaft (YK), the Massachusetts General Hospital Executive Committee on Research Fund for Medical Discovery (BCF), Aid for Cancer Research (BCF) and NIH grant 1K01CA140861 (BCF).

\section{Author Details}

'Division of Surgical Oncology, Massachusetts General Hospital Cancer Center and Harvard Medical School, Boston, USA, 2Department of Pathology, Massachusetts General Hospital Cancer Center and Harvard Medical School, Boston, USA and ${ }^{3}$ Division of Thoracic Surgery, Massachusetts General Hospital Cancer Center and Harvard Medical School, Boston, USA

Received: 30 November 2009 Accepted: 9 July 2010

Published: 9 July 2010

\section{References}

1. El-Serag HB, Rudolph KL: Hepatocellular carcinoma: epidemiology and molecular carcinogenesis. Gastroenterology 2007, 132:2557-76.

2. Simonetti RG, Camma C, Fiorello F, Politi F, D'Amico G, Pagliaro L: Hepatocellular carcinoma. A worldwide problem and the major risk factors. Dig Dis Sci 1991, 36:962-72.
3. Pierce RA, Glaug MR, Greco RS, Mackenzie JW, Boyd CD, Deak SB: Increased procollagen mRNA levels in carbon tetrachloride-induced liver fibrosis in rats. $\mathrm{J} \mathrm{Biol} \mathrm{Chem} \mathrm{1987,} \mathrm{262:1652-8.}$

4. Perez Tamayo R: Is cirrhosis of the liver experimentally produced by CCl4 and adequate model of human cirrhosis? Hepatology 1983, 3:112-20.

5. Shi J, Aisaki K, Ikawa Y, Wake K: Evidence of hepatocyte apoptosis in rat liver after the administration of carbon tetrachloride. Am J Pathol 1998, 153:515-25.

6. Manibusan MK, Odin M, Eastmond DA: Postulated carbon tetrachloride mode of action: a review. J Environ Sci Health C Environ Carcinog Ecotoxicol Rev 2007, 25:185-209.

7. Friedman SL: Molecular regulation of hepatic fibrosis, an integrated cellular response to tissue injury. J Biol Chem 2000, 275:2247-50.

8. Wu J, Zern MA: Hepatic stellate cells: a target for the treatment of liver fibrosis. J Gastroenterol 2000, 35:665-72.

9. Kordes C, Sawitza I, Muller-Marbach A, Ale-Agha N, Keitel V, KlonowskiStumpe H, Haussinger D: CD133+ hepatic stellate cells are progenitor cells. Biochem Biophys Res Commun 2007, 352:410-7.

10. Natarajan A, Wagner B, Sibilia M: The EGF receptor is required for efficient liver regeneration. Proc Natl Acad Sci USA 2007, 104:17081-6.

11. Tanabe KK, Lemoine A, Finkelstein DM, Kawasaki H, Fujii T, Chung RT, Lauwers GY, Kulu Y, Muzikansky A, Kuruppu D, Lanuti M, Goodwin JM, Azoulay D, Fuchs BC: Epidermal growth factor gene functional polymorphism and the risk of hepatocellular carcinoma in patients with cirrhosis. Jama 2008, 299:53-60.

12. Komuves $L G$, Feren $A$, Jones $A L$, Fodor E: Expression of epidermal growth factor and its receptor in cirrhotic liver disease. J Histochem Cytochem 2000, 48:821-30.

13. Sorkin A, Goh LK: Endocytosis and intracellular trafficking of ErbBs. Exp Cell Res 2009, 315:683-96.

14. Lai WH, Cameron PH, Wada I, Doherty JJ, Kay DG, Posner BI, Bergeron JJ: Ligand-mediated internalization, recycling, and downregulation of the epidermal growth factor receptor in vivo. J Cell Bio/ 109:2741-9.

15. Mead JE, Fausto N: Transforming growth factor alpha may be a physiological regulator of liver regeneration by means of an autocrine mechanism. Proc Natl Acad Sci USA 1989, 86:1558-62.

16. Yokoi Y, Namihisa T, Kuroda H, Komatsu I, Miyazaki A, Watanabe S, Usui K: Immunocytochemical detection of desmin in fat-storing cells (Ito cells). Hepatology 1984, 4:709-14.

17. Zalatnai A, Lapis K: Simultaneous induction of liver cirrhosis and hepatocellular carcinomas in F-344 rats: establishment of a short hepatocarcinogenesis model. Exp Toxicol Pathol 1994, 46:215-22.

18. Ferencz V, Horvath C, Kari B, Gaal J, Meszaros S, Wolf Z, Hegedus D, Horvath A, Folhoffer A, Szalay F: Bone disorders in experimentally induced liver disease in growing rats. World J Gastroenterol 2005, 11:7169-73.

19. Edwards JE, Dalton AJ: Induction of cirrhosis of the liver and of hepatomas in mice with carbon tetrachloride. J Natl Cancer Inst 1942, 3:19-41

20. Stowell RE, Lee CS, Tsuboi KK, Villasana A: Histochemical and microchemical changes in experimental cirrhosis and hepatoma formation in mice by carbon tetrachloride. Cancer Res 1951, 11:345-54

21. Belyaev ND, Budker VG, Deriy LV, Smolenskaya IA, Subbotin VM: Liver plasma membrane-associated fibroblast growth: stimulatory and inhibitory activities during experimental cirrhosis. Hepatology 1992 15:525-31.

22. Terai S, Sakaida I, Yamamoto N, Omori K, Watanabe T, Ohata S, Katada T, Miyamoto K, Shinoda K, Nishina H, Okita K: An in vivo model for monitoring trans-differentiation of bone marrow cells into functional hepatocytes. J Biochem 2003, 134:551-8.

23. Xue F, Takahara T, Yata Y, Kuwabara Y, Shinno E, Nonome K, Minemura M, Takahara S, Li X, Yamato E, Watanabe A: Hepatocyte growth factor gene therapy accelerates regeneration in cirrhotic mouse livers after hepatectomy. Gut 2003, 52:694-700.

24. Black D, Bird MA, Samson CM, Lyman S, Lange PA, Schrum LW, Qian T, Lemasters JJ, Brenner DA, Rippe RA, Behrns KE: Primary cirrhotic hepatocytes resist TGFbeta-induced apoptosis through a ROSdependent mechanism. J Hepatol 2004, 40:942-51.

25. Ozdogan M, Ersoy E, Dundar K, Albayrak L, Devay S, Gundogdu H: Beneficial effect of hyperbaric oxygenation on liver regeneration in cirrhosis. J Surg Res 2005, 129:260-4. 
26. Kim KH, Kim HC, Hwang MY, Oh HK, Lee TS, Chang YC, Song HJ, Won NH, Park KK: The antifibrotic effect of TGF-beta1 siRNAs in murine model of liver cirrhosis. Biochem Biophys Res Commun 2006, 343:1072-8.

27. Rudolph KL, Chang S, Millard M, Schreiber-Agus N, DePinho RA: Inhibition of experimental liver cirrhosis in mice by telomerase gene delivery. Science 2000, 287:1253-8,

28. Ishiki Y, Ohnishi H, Muto Y, Matsumoto K, Nakamura T: Direct evidence that hepatocyte growth factor is a hepatotrophic factor for liver regeneration and has a potent antihepatitis effect in vivo. Hepatology 1992, 16:1227-35.

29. Schiffer E, Housset $C$, Cacheux W, Wendum D, Desbois-Mouthon C, Rey C, Clergue F, Poupon R, Barbu V, Rosmorduc O: Gefitinib, an EGFR inhibitor, prevents hepatocellular carcinoma development in the rat liver with cirrhosis. Hepatology 2005, 41:307-14.

30. Kuriyama S, Yokoyama F, Inoue H, Takano J, Ogawa M, Kita Y, Yoshiji H, Deguchi A, Kimura Y, Himoto T, Yoneyama H, Kurokohchi K, Masaki T, Uchida N, Watanabe S: Sequential assessment of the intrahepatic expression of epidermal growth factor and transforming growth factor-beta1 in hepatofibrogenesis of a rat cirrhosis model. Int $\mathrm{J} \mathrm{Mol}$ Med 2007, 19:317-24.

31. El-Bassiouni A, Nosseir M, Zoheiry M, El-Ahwany E, Ghali A, El-Bassiouni N: Immunohistochemical expression of CD95 (Fas), c-myc and epidermal growth factor receptor in hepatitis $C$ virus infection, cirrhotic liver disease and hepatocellular carcinoma. Apmis 2006, 114:420-7.

32. Fausto N, Laird AD, Webber EM: Liver regeneration. 2. Role of growth factors and cytokines in hepatic regeneration. Faseb J 1995, 9:1527-36

33. Nagano K, Umeda Y, Saito M, Nishizawa T, Ikawa N, Arito H, Yamamoto S, Fukushima S: Thirteen-week inhalation toxicity of carbon tetrachloride in rats and mice. J Occup Health 2007, 49:249-59.

34. Desmouliere A: Hepatic stellate cells: the only cells involved in liver fibrogenesis? A dogma challenged. Gastroenterology 2007, 132:2059-62.

35. Noguchi S, Ohba Y, Oka T: Influence of epidermal growth factor on liver regeneration after partial hepatectomy in mice. J Endocrinol 1991, 128:425-31

36. Jones DE, Tran-Patterson R Jr, Cui DM, Davin D, Estell KP, Miller DM: Epidermal growth factor secreted from the salivary gland is necessary for liver regeneration. Am J Physiol 1995, 268:G872-8.

37. Daveau M, Scotte M, Francois A, Coulouarn C, Ros G, Tallet Y, Hiron M, Hellot MF, Salier JP: Hepatocyte growth factor, transforming growth factor alpha, and their receptors as combined markers of prognosis in hepatocellular carcinoma. Mol Carcinog 2003, 36:130-41.

38. Perugorria MJ, Latasa MU, Nicou A, Cartagena-Lirola H, Castillo J, Goñi S, Vespasiani-Gentilucci U, Zagami MG, Lotersztajn S, Prieto J, Berasain C, Avila MA: The epidermal growth factor receptor ligand amphiregulin participates in the development of mouse liver fibrosis. Hepatology 2008, 48:1251-61.

39. Tsuchiya A, Kamimura H, Takamura M, Yamagiwa S, Matsuda Y, Sato Y, Nomoto M, Ichida T, Aoyagi Y: Clinicopathological analysis of CD133 and NCAM human hepatic stem/progenitor cells in damaged livers and hepatocellular carcinomas. Hepatol Res 2009, 39:1080-90.

40. Uchida N, Buck DW, He D, Reitsma MJ, Masek M, Phan TV, Tsukamoto AS, Gage FH, Weissman IL: Direct isolation of human central nervous system stem cells. Proc Natl Acad Sci USA 2000, 97:14720-5.

41. Ma S, Chan KW, Hu L, Lee TK, Wo JY, Ng IO, Zheng BJ, Guan XY: Identification and characterization of tumorigenic liver cancer stem/ progenitor cells. Gastroenterology 2007, 132:2542-56.

42. Yin S, Li J, Hu C, Chen X, Yao M, Yan M, Jiang G, Ge C, Xie H, Wan D, Yang S, Zheng S, Gu J: CD133 positive hepatocellular carcinoma cells possess high capacity for tumorigenicity. Int J Cancer 2007, 120:1444-50.

\section{Pre-publication history}

The pre-publication history for this paper can be accessed here: http://www.biomedcentral.com/1471-230X/10/79/prepub

\section{doi: $10.1186 / 1471-230 X-10-79$}

Cite this article as: Fujii et al., Mouse model of carbon tetrachloride induced liver fibrosis: Histopathological changes and expression of CD133 and epidermal growth factor BMC Gastroenterology 2010, 10:79

\section{Submit your next manuscript to BioMed Central and take full advantage of:}

- Convenient online submission

- Thorough peer review

- No space constraints or color figure charges

- Immediate publication on acceptance

- Inclusion in PubMed, CAS, Scopus and Google Scholar

- Research which is freely available for redistribution 